\title{
COVID-19 pandemic and exercising: a cross-sectional study with 1156 patients with fibromyalgia
}

\author{
Isabela Paula Mundim Martins ${ }^{1 *}$ (D), Pedro Henrique Kopp Bodenmuller ${ }^{1}$ (D), \\ Daniel Bozza de Oliveira Mello ${ }^{1} \mathbb{B}$, Thelma Larocca Skare ${ }^{1}$
}

\begin{abstract}
SUMMARY
OBJECTIVE: The aim of this study was to analyze the effects of pandemic in the exercising practice and impact of the disease in patients with Fibromyalgia.

METHODS: This is a cross-sectional, Internet-based survey answered by 1156 individuals with Fibromyalgia diagnosis. Questions were on epidemiology, social distancing habits, and exercise practice before and after COVID-19 pandemic, including subtypes of exercises (for resistance, flexibility, balance, and strength). The Fibromyalgia Impact Questionnaire was applied.

RESULTS: In the whole sample, $57.7 \%$ of individuals practiced exercises before pandemic; during pandemic, only $34.8 \%$ practiced and $39.6 \%$ left this practice. Among those taking quarantine $(n=440), 52.9 \%$ used to do exercises prior to pandemic; in the pandemic, $28.1 \%$ (reduction of $53.2 \%$ ). The median Fibromyalgia Impact Questionnaire among those who practiced exercises in the pandemic was 73.6 (61.1-83.2) and that among those who did not was 80.4 (71.9-86.9), with $p<0.0001$. The Fibromyalgia Impact Questionnaire did not change according to the type of physical exercise $(p=0.27)$.

CONCLUSION: A high proportion of patients with Fibromyalgia stopped exercising during COVID-19 pandemic; as a result, the impact of the disease during this period was worse among those not practicing exercises.

KEYWORDS: Fibromyalgia. Pandemics. Exercise. COVID-19.
\end{abstract}

\section{INTRODUCTION}

In November 2019, an increasing number of acute respiratory distress syndrome (ARDS) was reported in Wuhan, a city in the Chinese province of Hubei, and in January 2020, a new coronavirus was identified as the etiological agent responsible for this alarming crescent cases of ARDS ${ }^{1}$. At the same month, the World Health Organization (WHO) declared the outbreak of the novel coronavirus - at the time called 2019-nCoV - a Public Health Emergency of International Concern ${ }^{1}$. The first case reported in Brazil was on February 26, 2020, and, due to the escalating number of confirmed cases, the Brazilian Health Authorities implanted several measures to prevent virus spreading. Due to the nonavailability of effective treatment and due to the lack of an effective vaccine, the main strategy to contain the infection proliferation was to inhibit the person-to-person contamination by social distancing, social isolation, and quarantine ${ }^{1}$.

Social distancing is defined as the separation of a sick person with a contagious disease from noninfected persons to protect this second group. Quarantine is an incredibly old and effective tool to control the spread of a contagious infection ${ }^{2,3}$. Although these terms are distinguished by definition, they are interchangeable in public communication and are used likewise in this article 3 .

Several studies have been done concerning the effects of social distancing in the health spectrum; significant impact on psychological well-being, emotional health, and practice of

'Faculdade Evangélica Mackenzie do Paraná - Curitiba (PR), Brazil.

*Corresponding author: isabelapmundimm@gmail.com

Conflicts of interest: the authors declare there are no conflicts of interest. Funding: none.

Received on July 22, 2021. Accepted on August 16, 2021. 
physical exercise has been reported ${ }^{4}$. Such factors may have had a special influence on the population with fibromyalgia $(\mathrm{FM})^{5}$.

FM is a musculoskeletal syndrome characterized by chronic and diffuse pain of unknown etiology ${ }^{6}$. It affects $2.5 \%$ of the population worldwide, mostly women aged $30-55$ years 7 . In this disease, pain perception is increased and often associated with chronic headache, fatigue, sleep disturbances, depression, anxiety, and nonspecific urethral syndrome ${ }^{5,7}$. The first approach to FM treatment is patient education. Key elements in the patient's education encompass the reassurance that FM is a real illness, information about general aspects of pain and its neurophysiology, and explanations on the influence of stress and mood disorders on the symptoms, among others. The importance of physical exercises in reducing pain and improving general, psychological, and emotional aspects of the patients with FM should also be emphasized ${ }^{8,9}$.

In this study, the objective was to analyze the impact of the SARS-CoV-2 pandemic on patients with FM, practice of exercises, and its consequences in the patient's symptomatology.

\section{METHODS}

This is a cross-sectional study based on an Internet questionnaire and was approved by the local Committee of Ethics in Research under protocol 4.106.704 and date June 23, 2020.

To answer the questionnaire, the participants should tick concordance with a consent term. The questionnaire was intended to patients aged 18 years or older with FM and with a previous diagnosis of FM done by a doctor. It was applied from June 24, 2020, to August 31, 2020, through Google Forms using closed, multiples choices questions and questions with short answers and announced on Facebook, Instagram, and WhatsApp groups.

Data collection included epidemiological and clinical information (age, sex, local of residency, disease duration), questions on exercise practice prior to quarantine (including exercise subtype), questions on persistence of exercise practice during pandemic (and, if positive, on exercise subtypes), and questions on isolation. Patients physical exercises practice was classified into exercises for resistance (walking, swimming, etc.), for strength (bodybuilding, weightlifting, etc.), for flexibility (Pilates, stretching, etc.), and for equilibrium (tai-chi, yoga, etc.). The Fibromyalgia Impact Questionnaire (FIQ) was applied. The FIQ is an instrument that measures functional ability and symptoms severity in patients with FM and that has a validated Brazilian-Portuguese version ${ }^{10}$. It consists of 21 individual questions that are answered in a $0-10$-point rating scale, with 10 indicating the worst scenario. This instrument measures how the patient feels in the past seven days. The total score ranges from $0-100$.
Data were collected and expressed in percentage in frequency tables. Shapiro-Wilk test was used to analyze data distribution; central tendency was expressed in median and interquartile range (IQR) if data were nonparametric and mean and standard deviation (SD) were parametric. Comparison of two series of nominal data was done by Mann-Whitney U test (FIQ values in those practicing and not practicing physical exercises); comparison of more than two was done by Kruskal-Wallis test (FIQ values according to exercises subtypes). The accepted significance was 5\%. The software Graph Pad Prism version 6.01 was used for calculations.

\section{RESULTS}

The questionnaire was answered by 1176 individuals. Of these, 20 patients were excluded because they did not confirm that the FM diagnosis was done by a doctor. Table 1 provides details on the duration of FM and epidemiological data of the patients. It is found that most of the patients were middle-aged females and the disease duration was more than 5 years.

Of the 1156 individuals, approximately $116(10.3 \%)$ stayed isolated in 50\% or less of the time and 1040 (89.9\%) in more than $50 \%$ of the time. Again of these 1040 individuals, 440 (42.3\%) had some social isolation and were kept quarantine.

In the studied sample, the FIQ score had a median of 79.1 (IQR 69.1-86.3).

Table 2 lists patients who practiced some type of physical activity prior to and during the pandemic. This table also shows the degree of reduction in the physical activity during pandemics.

Table 3 shows the same comparison, but in the sample that kept quarantine. Both Tables 2 and 3 display

Table 1. Epidemiological data and disease duration in 1156 patients with fibromyalgia.

\begin{tabular}{l|c}
\hline Median age (years) & $\begin{array}{c}42 \text { (interquartile } \\
\text { range 36-48) }\end{array}$ \\
\hline Females/males (\%) & $1099(95.06) / 57(4.9)$ \\
\hline Residency* & $151 / 1152(13.1)$ \\
\hline Midwest region (\%) & $200 / 1152(17.3)$ \\
\hline Northeast region (\%) & $53 / 1152(4.5)$ \\
\hline North region (\%) & $486 / 1152(42.1)$ \\
\hline Southeast region (\%) & $262 / 1152(22.7)$ \\
\hline South region (\%) & \\
\hline Disease duration (year) & $179(15.4)$ \\
\hline$>1(\%)$ & $349(30)$ \\
\hline $1-4(\%)$ & $628(54.3)$ \\
\hline$<5(\%)$ &
\end{tabular}

*Brazilian regions. 
that the biggest reduction occurred in those who practice strength exercises.

In the whole sample, the median FIQ was 79.1 (IQR 69.186.3). The comparison of FIQ results in those who did any type of exercises with those who did not is shown in Figure 1.

When the domain "pain" of the FIQ was analyzed separately, the obtained results in the whole sample had a median visual analog scale (VAS) of 9 (IQR 8-10). The median VAS of pain in those not practicing exercise was 9 (IQR 8-10) and that in those practicing exercises was 8 (IQR 7-9), with $\mathrm{p}<0.0001$.

In those who kept exercising during pandemic, the median FIQ according to the exercise subtype is given in Table 4. It is found that the subtype of exercise did not change the FIQ.

\section{DISCUSSION}

Data collected in this study show that the exercise practicing in patients with FM was highly influenced by COVID-19 pandemic, with almost $40 \%$ of those who practiced regular exercises leaving this practice; in those who kept quarantine, almost half of them stopped exercising. We also found that the impact of the FM was worse in those who did not practice exercise, although no causal relationship can be inferred of this. We also found no differences in the FIQ according to exercise subtype that was done.
The treatment of patients with FM is usually multidisciplinary and difficult as most of the available options offer a modest effect. The 2017 revised European League Against Rheumatism report stated that the only "strong" therapy recommendation for the treatment of FM was exercise?

The obtained data on physical exercise neglecting during pandemic is alarming and deserves attention. Patients with FM are known to have low adherence to exercises under normal

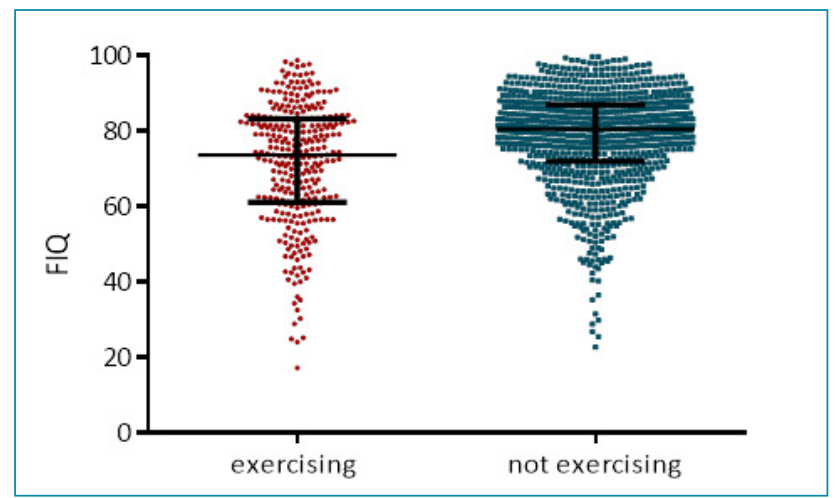

Figure 1. Comparison of Fibromyalgia Impact Questionnaire between individuals exercising and not exercising during COVID-19 pandemic. Exercising: median Fibromyalgia Impact Questionnaire 73.6 (61.1-83.2); not exercising: median Fibromyalgia Impact Questionnaire 80.4 (71.9-86.9) with $\mathrm{p}<0.0001$.

Table 2. Frequency of physical exercising in patients with fibromyalgia prior to and during the COVID-19 pandemic* .

\begin{tabular}{l|c|c|c|c} 
& $\begin{array}{c}\text { Prior to } \\
\text { pandemic }\end{array}$ & $\begin{array}{c}\text { During the } \\
\text { pandemic }\end{array}$ & $\begin{array}{c}\text { Reduction of exercising } \\
\text { during pandemic }\end{array}$ & $\begin{array}{c}\text { Individuals who used to } \\
\text { practice but stopped exercising }\end{array}$ \\
\hline Resistance (\%) & $406 / 1156(35.1)$ & $172 / 1156(14.8)$ & $234 / 1156(20.2)$ & $234 / 406(57.6)$ \\
\hline Strength (\%) & $155 / 1156(13.4)$ & $43 / 1156(3.7)$ & $112 / 1156(9.6)$ & $112 / 155(72.2)$ \\
\hline Flexibility (\%) & $273 / 1156(23.6)$ & $150 / 1156(12.9)$ & $123 / 1156(10.6)$ & $123 / 273(30.2)$ \\
\hline Balance (\%) & $44 / 1156(3.8)$ & $30 / 1156(2.5)$ & $14 / 1156(1.2)$ & $14 / 44(31.8)$ \\
\hline Any exercise (\%) & $668 / 1156(57.7)$ & $403 / 1156(34.8)$ & $265 / 1156(22.9)$ & $265 / 668(39.6)$ \\
\hline
\end{tabular}

* More than one category of physical activity was possible to be checked by the interviewee.

Table 3. Frequency of physical exercising in patients with fibromyalgia prior to and during the COVID-19 pandemic and who kept quarantine $(n=440)$ *

\begin{tabular}{l|c|c|c|c} 
& $\begin{array}{c}\text { Prior to } \\
\text { pandemic }\end{array}$ & $\begin{array}{c}\text { In the } \\
\text { pandemic }\end{array}$ & $\begin{array}{c}\text { Reduction of exercising } \\
\text { during pandemic }\end{array}$ & $\begin{array}{c}\text { Individuals who used to } \\
\text { practice but stopped exercising }\end{array}$ \\
\hline Resistance (\%) & $147 / 440(33.4)$ & $66 / 440(15.0)$ & $81 / 440(18.4)$ & $81 / 147(55.1)$ \\
\hline Strength (\%) & $42 / 440(9.5)$ & $9 / 440(2.0)$ & $33 / 440(7.55)$ & $33 / 42(78.5)$ \\
\hline Flexibility (\%) & $90 / 440(20.4)$ & $63 / 440(14.35)$ & $27 / 440(6.1)$ & $27 / 90(30.0)$ \\
\hline Equilibrium (\%) & $21 / 440(4.7)$ & $11 / 440(2.5)$ & $10 / 440(2.2)$ & $10 / 21(47.6)$ \\
\hline Any exercise (\%) & $233 / 440(52.9)$ & $124 / 440(28.1)$ & $109 / 440(24.7)$ & $109 / 233(46.7)$ \\
\hline
\end{tabular}

* More than one category of physical activity was possible to be checked by the interviewee. 
Table 4. Comparison of Fibromyalgia Impact Questionnaire (FIQ) during COVID-19 pandemic according to exercises subtypes.

\begin{tabular}{l|c|c} 
& $\begin{array}{c}\text { Median Fibromyalgia } \\
\text { Impact Questionnaire } \\
\text { (interquartile range) }\end{array}$ & \multirow{2}{*}{ p-value } \\
Resistance & $73.4(57.1-82.4)$ & \multirow{2}{*}{0.27} \\
\hline Flexibility & $71.0(60.3-83.2)$ & \\
\hline Strength & $67.1(50.8-77.6)$ & \\
\hline Equilibrium & $66.4(57.5-82.0)$ & \\
\hline
\end{tabular}

circumstances and our results showed that even before pandemic only half of them used to exercise ${ }^{11}$. During pandemic, another half of those who practiced exercise abandoned this routine.

Practicing exercises in public spaces favors social interaction, and this has also beneficial aspect in FM as those patients are prone to depression and anxiety ${ }^{11}$. Therefore, closing of gyms, sports clubs, and public spaces not only affects the physical conditioning but also aggravates the social isolation and its psychological repercussions.

Prior to the pandemic, the most practiced activities were those of resistance, which is a modality of easy access, low cost, safe, and efficient in the treatment of $\mathrm{FM}^{12}$. They were found to improve general well-being, symptoms, and cardiovascular capacity better than activities of flexibility ${ }^{13}$.

Strength exercises suffered the biggest reduction in practice during pandemic (72.2\%), which can be explained by the diffculty of maintaining, for example, weight training - the group's main activity - while the gyms are closed. They consist of a restricted number of series and repetitions movements that utilize a resisted tension and recruit a set of musculotendinous bone structures, with or without load application ${ }^{13}$.

Flexibility and balance modalities had the smallest decrease in practice during the pandemic (30.2 and 31.8\%, respectively). This is probably due to the fact that most of these activities can be carried on in isolation, outside a specific environment and generally are well-tolerated exercises ${ }^{14}$. Flexibility exercises uses movements with high-level amplitude, using one or more joints with the objective of recruiting the main muscles and joint structures ${ }^{14}$. Balance exercises consist of techniques aiming to acquire stability and body awareness through the practice of postures, respiratory control, and meditative techniques ${ }^{15}$.

Regardless of the type of exercise (resistance, strength, flexibility, and balance), the FIQ did not change significantly when one modality was compared to another. The comparison of the different modalities of exercises is difficult mainly due to variations in intensity, frequency, and specific characteristics of each activity and by the fact that patients may combine different subsets of exercises. Therefore, until now, it cannot be said that there is evidence that one exercise is more efficient than another. Despite of this, the FIQ of those who practice any type of exercise was better than those not exercising. It is shown that they do influence pain, sleep, and general well-being, in addition to improving cardiovascular conditioning and overall morbidity and mortality ${ }^{16,17}$.

The biological mechanisms involved in the analgesic effects of exercises are not completely understood. They seem to result from an interplay among endogenous opioid system, the endocannabinoid system, and serotoninergic system. This interaction results in a multisegmented decrease in pain sensitivity ${ }^{16}$. Besides, exercises have shown to change brain-derived neurotrophic factor (BDNF) serum levels that are altered in FM and that affects neuronal plasticity acting in the pain sensitization ${ }^{18}$.

This study has several limitations. It was based on information that the patients had a FM diagnosis and it was not possible to grade the amount of exercises done. Also, the FM tendency for pain catastrophizing, which is characterized as a negative psychosocial construction of the pain, may suffer influence of other aspects than changes in the physical exercising ${ }^{19}$. Quarantine brought stress, which is a precipitating factor for augmentation in the pain perception, and this may have resulted in a momentary distortion of the FIQ score ${ }^{19,20}$. Finally, stipulating classifications of physical exercises modalities is a great challenge, since each person has particularities for their own practice, and it is not possible to establish a standard approach for the entire sample. However, this work has the merit of showing a great alteration of exercising habits in this sample of patients with FM during pandemic and its possible influence in the impact of this disease.

Educating patients about the importance of physical exercise is fundamental and, at this moment, guiding them to practice physical activity in an adapted way, at home and/or with support via Internet, is essential. It is also extremely necessary that patients who have already adhered to this form of treatment do not fail to pursuit it, mainly in the current atypical circumstances of pandemic and social isolation that, by themselves, tend to worsen the FM symptoms.

\section{CONCLUSIONS}

There was a decreased of physical activity by patients with FM during pandemic, thus worsening the impact of this disease. All subtypes of exercises seem to be beneficial in this context as no differences in the FIQ score could be detected among them.

\section{ACKNOWLEDGMENT}

The authors thank the Associação Paranaense dos Fibromialgicos (APAFIBRO) and Associação Brasileira dos Fibromialgicos (ABRAFIBRO) for their support in data collection and disclosure of questioner. 


\section{AUTHORS" CONTRIBUTIONS}

IPMM: Conceptualization, Data curation, Formal analysis, Writing - original draft, Writing - review \& editing. PHKB: Conceptualization, Data curation, Formal analysis, Writing
- original draft, Writing - review \& editing. DBOM: Data curation, Formal analysis, Writing - original draft, Writing review \& editing. TLS: Data curation, Formal analysis, Writing - original draft, Writing - review \& editing.

\section{REFERENCES}

1. Garrido RG, Garrido FSRG. COVID-19: an outlook with emphasis on restrict measures of interpersonal contact. Interfaces Cientificas: Saude e Ambiente. 2020;8(2):127-41. https://doi.org/10.17564/2316-3798.2020v8n2

2. Wilder-Smith A, Freedman DO. Isolation, quarantine, social distancing and community containment: pivotal role for old-style public health measures in the novel coronavirus (2019-nCoV) outbreak. J Travel Med. 2020;27(2):taaa020. https://doi.org/10.1093/jtm/taaa020

3. Brooks SK, Webster RK, Smith LE, Woodland L, Wessely S, Greenberg N, et al. The psychological impact of quarantine and how to reduce it: rapid review of the evidence. Lancet. 2020;395(10227):912-20. https://doi.org/10.1016/S01406736(20)30460-8.

4. Bezerra ACV, Silva CEMD, Soares FRG, Silva JAMD. Factors associated with people's behavior in social isolation during the COVID-19 pandemic. Cienc Saude Colet. 2020;25(Suppl 1):241121. https://doi.org/10.1590/1413-81232020256.1.10792020

5. Galvez-Sánchez CM, Duschek S, Paso GAR. Psychological impact of fibromyalgia: current perspectives. Psychol Res Behav Manag. 2019;12:117-27. https://doi.org/10.2147/PRBM.S178240

6. Santos EB, Quintans Junior LJ, Fraga BP, Macieira JC, Bonjardim LR. Avaliação dos sintomas de ansiedade e depressão em fibromiálgicos [An evaluation of anxiety and depression symptoms in fibromyalgia]. Rev Esc Enferm USP. 2012;46(3):590-6. Portuguese. https://doi.org/10.1590/ s0080-62342012000300009

7. Lorena SB, Pimentel EAS, Fernandes VM, Pedrosa MB, Ranzolin A, Duarte ALBP. Evaluation of pain and quality of life of fibromyalgia patients. Rev Dor. 2016;17(1):8-11. https://doi. org/10.5935/1806-0013.20160003

8. Valim V, Natour J, Xiao Y, Pereira AF, Lopes BB, Pollak DF, et al. Effects of physical exercise on serum levels of serotonin and its metabolite in fibromyalgia: a randomized pilot study. Rev Bras Reumatol. 2013;53(6):538-41. https://doi.org/10.1016/..rbr.2013.02.001

9. Macfarlane GJ, Kronisch C, Dean LE, Atzeni F, Häuser W, Fluß $E$, et al. EULAR revised recommendations for the management of fibromyalgia. Ann Rheum Dis. 2017;76(2):318-28. https:// doi.org/10.1136/annrheumdis-2016-209724

10. Marques AP, Santos AMB, Assumpção A, Matsutani LA, Lage LV, Pereira CAB. Validation of the Brazilian version of the fibromyalgia impact questionnaire (FIQ). Rev Bras Reumatol. 2006;46(1):2431. https://doi.org/10.1590/S0482-50042006000100006
11. Valim V. Benefits of exercise in the fibromyalgia. Rev Bras Reumatol. 2006;46(1):49-55. https://doi.org/10.1590/S048250042006000100010

12. Busch AJ, Webber SC, Richards RS, Bidonde J, Schachter CL, Schafer LA, et al. Resistance exercise training for fibromyalgia. Cochrane Database Syst Rev. 2013;2013(12):CD010884. https://doi.org/10.1002/14651858.CD010884

13. Brosseau L, Wells GA, Tugwell P, Egan M, Wilson KG, Dubouloz $C J$, et al. Ottawa panel evidence-based clinical practice guidelines for strengthening exercises in the management of fibromyalgia: part 2. Phys Ther. 2008;88(7):873-86. https:// doi.org/10.2522/ptj.20070115

14. Kim SY, Busch AJ, Overend TJ, Schachter CL, van der Spuy I, Boden C, et al. Flexibility exercise https://doi.org/10.1590/S048250042006000100008 training for adults with fibromyalgia. Cochrane Database Syst Rev. 2019;9(9):CD013419. https:// doi.org/10.1002/14651858.CD013419

15. Silva GDA, Lage LV. Yoga and fibromyalgia. Rev Bras Reumatol. 2006;46(1):37-9. https://doi.org/10.1590/S048250042006000100008

16. Rice D, Nijs J, Kosek E, Wideman T, Hasenbring MI, Koltyn K, et al. Exercise-induced hypoalgesia in pain-free and chronic pain populations: state of the art and future directions. J Pain. 2019;20(11):1249-66. https://doi.org/10.1016/j. jpain.2019.03.005

17. Squires RW, Shultz AM, Herrmann J. Exercise training and cardiovascular health in cancer patients. Curr Oncol Rep. 2018;20(3):27. https://doi.org/10.1007/s11912-018-0681-2

18. Nugraha B, Karst M, Engeli S, Gutenbrunner C. Brain-derived neurotrophic factor and exercise in fibromyalgia syndrome patients: a mini review. Rheumatol Int 2012;32(9):2593-9. https://doi.org/10.1007/s00296-011-2348-2

19. Izquierdo-Alventosa $R$, Inglés $M$, Cortés-Amador $S$, Gimeno-Mallench L, Chirivella-Garrido J, Kropotov J, et al. Low-intensity physical exercise improves pain catastrophizing and other psychological and physical aspects in women with fibromyalgia: a randomized controlled trial. Int J Environ Res Public Health. 2020;17(10):3634. https://doi.org/10.3390/ ijerph17103634

20. Campos JADB, Martins BG, Campos LA, Marôco J, Saadiq RA, Ruano R. Early psychological impact of the COVID-19 pandemic in brazil: a national survey. J Clin Med. 2020;9(9):2976. https:// doi.org/10.3390/jcm9092976 